\title{
Breves consideraciones sobre ¿Por qué se suicidan los escritores de literatura?**
}

\author{
Brief considerations on why the writers \\ of literature commit suicide?
}

\author{
Breves considerações sobre por que os escritores \\ de literatura se suicidam?
}

\footnotetext{
* Médico y Cirujano Universidad de Caldas. Magister en Salud Pública Universidad del Valle. Máster en Psicogeriatría Universidad Autónoma de Barcelona, España. Magister en Literatura Universidad Tecnológica de Pereira y estudiante del Doctorado de Literatura en la misma Universidad. Actualmente es profesor de la Facultad de Ciencias de la Salud y del Doctorado en Educación de la Universidad Tecnológica de Pereira. Ha recibido la distinción Viday obra a la psiquiatría, 2015 máxima distinción a un psiquiatra por la Asociación Colombiana de Psiquiatría. Miembro Honorario de la Academia Nacional de Medicina, Expresidente de la Asociación Colombiana de Psiquiatría. Correo electrónico: alarcon@utp.edu.co

** Este artículo hace parte de la investigación para optar a la condición de candidato a Doctorado en Literatura en la Universidad Tecnológica de Pereira intitulada Suicidio: palimpsesto en la escritura de cinco autores latinoamericanos. Artículo de investigación recibido el 10/08/2015 y aceptado el 14/11/2015.
} 


\section{Cómo citar}

PATROCinio ALARCON, R. (2015). Breves consideraciones sobre ¿Por qué se suicidan los escritores de literatura? Revista CS, no. 17, pp. 63-82. Cali, Colombia: Facultad de Derecho y Ciencias Sociales, Universidad Icesi.

DOI: http://dx.doi.org/10.18046/recs.i17.2041 


\section{Resumen}

Abstract

Resumo

Este artículo busca iniciar un debate acerca de la muerte de los escritores de literatura y de sus personajes con factores que tengan la misma inquietud. Evitando la tentación de impregnar el papel de exposiciones teóricas sobre las diversas causas del suicidio en una persona. No obstante la presencia de factores comunes, aquí se apunta a reconocer la existencia de motivos particulares y específicos en cada suicida. Si bien se han escrito innumerables tratados y obras literarias sobre el suicidio, estos siguen enfoques religiosos, filosóficos, socio-antropológicos, económicos, médicos y psiquiátricos, y genéticos, principalmente. Por lo tanto, sin una pretensión de agotar el tema, antes que cerrar con ideas concluyentes, se formulan preguntas para continuar con la reflexión sobre el fenómeno del suicidio.

\section{PALABRAS CLAVE:}

Suicidio | escritores | literatura

This article pursues the objective is to initiate a debate on the concerns regarding the death of literature writers and their characters, avoiding the temptation to impregnate the paper theoretical presentations on the various causes of suicide of a person. Avoiding the temptation to fill up the paper with theoretical arguments on the various causes of the suicide of a person, even with the presence of common factors, here it aims to recognize the existence of particular specific reasons in each suicide. Many treaties and literary works have been written on suicide, mainly with a religious, philosophical, socio-anthropological, economic, medical and psychiatric and genetic approaches. Thus, without claiming to exhaust the subject, rather than closing with concluding thoughts, some questions are formulated to continue the reflection on the phenomenon of suicide.

\section{KEYWORDS:}

Suicide | writers | literature 
Este artigo persegue o objetivo de iniciar um debate sobre a inquietação relacionada com a morte dos escritores de literatura e de seus personagens. Evitando a tentação de impregnar o papel de exposições teóricas sobre as diversas causas do suicídio em uma pessoa, não obstante a presença de fatores comuns, aqui se visa reconhecer a existência de motivos particulares e específicos em cada suicida. Se bem é certo que têm sido escritos inúmeros tratados e obras literárias sobre o suicídio, estes seguem enfoques religiosos, filosóficos, sócio antropológicos, econômicos, médicos e psiquiátricos, e genéticos, principalmente. Portanto, sem uma pretensão de esgotar o tema, antes que encerrar com ideias conclusivas, se formulam algumas perguntas para continuar com a reflexão sobre o fenômeno do suicídio.

PALAVRAS CHAVES:

Suicídio | escritore | literatura 


\section{Corpus textual}

Un concepto, para mí, trillado y casi un cliché es que el suicidio es el triunfo de Tánatos sobre Eros: se afirma además que la forma más violenta de morir es el suicidio. Estas premisas pueden ser temerarias y estar impregnadas de cierto dogmatismo que, como tal, carece de reflexión, pues es común el suicidio de escritores sin ningún sello de violencia, si esta se considera el acto de hacer daño a sí mismo o a otros mediante el sufrimiento corporal. Debemos revisar si toda muerte es el triunfo de Tánatos, pues algunos han considerado su suicidio dentro del ámbito del principio de Erosy del placer.

Es imposible abordar el tema sin remitirnos a los antiguos filósofos griegos que elaboraron dos ideas fundamentales. Primero, la idea de Platón de que el alma es inmortal, dando lugar a diversas interpretaciones según donde uno se ubique. Se podía pensar con esta idea platónica que lo que el suicida mata es su cuerpo, no su alma, y consecuentemente podría preguntarse: si mi alma sigue existiendo, y con la carga de tormentos, ¿para qué me suicido?, ¿será que matando el cuerpo mato mis sufrimientos? Hecho improbable, a mí parecer, puesto que los sufrimientos son más propios de la existencia-especialmente entre escritores y sus personajes-que de sus padecimientos físicos: ejemplo de ello es Emma Bovary.

Algunos podrían preguntar ¿qué es la existencia? Podríamos contestarles que es la forma como cada quien construye su psique y el modo como se relaciona con el mundo externo, asumiendo una perspectiva de sí mismo y de su entorno. Cuando hablo de psique me refiero al contexto de sus pensamientos, emociones y comportamientos, en una palabra: existencia. Por ello, puedo afirmar que la urdimbre que el escritor teje hace que los personajes construyan su psique propia e inigualable: $y$ por tanto existen, al igual que los seres humanos.

Creo que el postulado platónico es ambivalente y contradictorio para el suicida literario. José Asunción Silva ¿buscaba la inmortalidad de su alma? Exploremos esta pregunta en su poema La Última Despedida (Silva, 1984): ${ }^{1}$

\footnotetext{
La muerte:

Yo soy la luz y sin embargo temen

Los hombres encontrarme,

Yo soy la misericordia soñadora

Que los espacios abren.

¡Dudáis!...oíd las voces

Que del sepulcro salen
}

1. Se transcribe el poema en forma exacta como aparece en la página 54 de Asunción Silva José (1984) Joyas de la literatura colombiana. 
Los cuerpos:

Nosotros vamos de la madre tierra

A la región oscura,

Nosotros vamos a perdernos ora

En la vida fecunda

Que en los profundos senos

De la muerte murmura.

Los recuerdos:

Nosotros viviremos en las almas,

De aquellos que os sintieron

A su lado pasar en vuestra vida.

¡Aquí sobre la tierra

Nosotros mantendremos

Vuestra memoria fresca!

Las almas:

Nosotras vamos de la vida eterna

A proseguir la ruta,

Nosotras vamos a tender el vuelo

A regiones más puras,

¡Como es la luz de bella,

Tras las vagas brumas!

En este poema de Silva es evidente la ambivalencia ante la muerte. Por un lado, la muerte como final de todo, quedando sólo el recuerdo de los vivos; por otro lado, la muerte como inicio de una nueva vida en "regiones más puras".

El segundo hecho, de los griegos antiguos, me parece interesantísimo e invito a su reflexión. Existió un tribunal (Alarcón, 2013) en donde el sujeto que deseaba suicidarse debía acudir para explicar sus razones, una vez expuestas se le autorizaba o no su suicidio, sin ningún escarnio público y sin consecuencias para su familia; si no acudía al tribunal la deshonra caía sobre él y su familia. Esto implicaba que todo futuro suicida debía considerar y reflexionar sobre el morir, se evitaba el suicidio impulsivo y sin fundamentación, y posiblemente también el suicidio aparentemente razonado. A los lectores positivistas y pragmáticos no les puedo ofrecer estadísticas sobre cuántos suicidios se evitaron o se consumaron por el empleo de estos tribunales, puesto que en esa época nadie se preocupaba por llevar registros de los sucesos o de su ausencia; la estadística en medicina se utiliza como método durante el período moderno hasta asfixiarnos de datos en la postmodernidad.

Si estableciéramos en la época actual el modelo de los tribunales griegos, nos llevaría a una confrontación ideológica y existencial que nos podría brindar cono- 
cimiento de primera mano sobre por qué se suicidan los escritores de literatura, sin asegurar que no se suiciden.

A mi modo de ver, los literatos han generado sus propios tribunales para exponer sus motivos de suicidio, unas veces en sus obras literarias a través de los personajes construidos que habitaban en su interior; en otras con posturas personales en sus ensayos o artículos. Un ejemplo es el filósofo y escritor rumano-francés E. M. Ciorán, quien reflexionó tanto sobre su suicidio y nunca lo llevó a cabo, terminando con una enfermedad de Alzheimer y olvidándose de esa posibilidad.

En el suicidio de los escritores de literatura invito a considerar dos instancias: la primera, el suicidio desde la visión introspectiva del escritor, o sea en el mundo psíquico formado por el escritor; la segunda, el suicidio por la visión hacia afuera, inmersa en la cultura del escritor.

Antes de exponer argumentos sobre las dos instancias mencionadas, me asaltan unos pensamientos en forma de pregunta: ¿el suicidio de los escritores de literatura es diferente y obedece a consideraciones distintas del suicidio de la gente común, del ciudadano no literato?, temo que sí, en cuanto a las consideraciones de quitarse la vida, presumiendo que el literato no realiza el suicidio de forma impulsiva, sino que, por el contrario, sus motivaciones tienen una gran carga de cuestionamientos y reflexiones ante un tribunal griego propio.

Es posible que algunas formas de suicidarse sean las mismas del ciudadano común, como por ejemplo: con arma de fuego (José Asunción Silva, Heinrich von Kleist, Mario de Sá Carneiro, Candelario Obeso); ahorcándose (Jens Bjorneboe); arrojándose al vacío de un precipicio o de las aguas (José Agustín Goytisolo, Alfonsina Storni, Virginia Woolf); consumiendo venenos (Leopoldo Lugones, Thomas Chatterton, Horacio Quiroga); mezclando medicamentos y alcohol o con un exceso de ellos (Cesare Pavese, Bernardo Arias Trujillo, Andrés Caicedo, María Mercedes Carranza); abandonando tratamientos para enfermedades orgánicas (¿Fernando Pessoa?); viviendo vidas temerarias o degradantes (Annemarie Schwarzenbach). El cuestionamiento de estos suicidios no es la forma del suicidio sino el porqué: qué pretende al provocarse deliberadamente la muerte o al hacer que sus personajes, ejes de las narraciones, mueran.

Otra postura frecuente en el campo de la medicina pragmática, positivista y reduccionista que impera en el mundo occidental, y desgraciadamente a mi parecer donde está actualmente la psiquiatría, es considerar que todo suicida padece un trastorno mental. Se suma a ello, el estigma de que si pertenece al mundo de las artes, especialmente de la literatura, es un individuo sufriente patológico mental, incapaz de adaptarse a las demandas de la época postmoderna y de las tecnologías, por lo cual cae en la desolación y en la ambivalencia afectiva. Oigo decir con frecuencia en los pasillos de las clínicas y hospitales, al comentar sobre el suicidio de un artista: "era un incompetente desadaptado, que más se podría esperar". Nada más falso y alejado de la realidad que esta afirmación. 


\section{El suicidio desde la visión introspectiva del escritor}

Esta perspectiva nos lleva a considerar la construcción de su psique y su dinámica. Sabemos que nacemos con unas potencialidades biológicas que pueden ser desarrolladas o estancadas, dependiendo de la riqueza o no del medio ambiente en que se vive. A la vez, cada individuo introyecta el mundo a su manera, dándole un significado y generando respuestas. La estructura yoica como fuerza catalizadora, reguladora y equilibrante determina en sí las formas de expresión del individuo, de acuerdo al éxito o al fracaso de sus relaciones con el Ello, o sea con los instintos del placer, conservación y muerte, y con las fuerzas normativas de la conciencia del Superyó.

Para el escritor de literatura que se enfrenta a la idea suicida de sí mismo o de sus personajes -variaciones del sí mismo pues son frutos de su conciencia y de sus instintos- la muerte y el placer adquieren una dimensión especial. Esta fuerza instintiva invade al Yo y lo domina, y cuando se enfrenta al Superyó no encuentra un oponente sino un aliado que mediante la razón justifica el acto suicida. Esta es una de las diferencias del suicidio del literato del hombre común: las fuerzas instintivas del Ello aliadas con las fuerzas normativas del Superyó, no en contraposición. ${ }^{2}$ ¿El papel del Yo es empobrecido o aniquilado? Se creerá, pero no es así, el Yo madura y estructura una nueva visión de la vida que no es nada más que la muerte: "Si quieres vivir feliz, prepárate para la muerte" se lee a la entrada de las catacumbas de San Esteban en la vía Apia en Roma.

Se podría pensar que el suicidio del hombre o de la mujer de la literatura no es más que una hostilidad hacia el sí mismo real, el cual no se acepta al sentirse frustrado como ser o al cuestionar las bases de su existencia, como los proyectos inherentes a ella, consumados o inalcanzados. Es la agresión dirigida hacia sí mismo, dirán algunos psicoanalistas, con razón desde esta consideración. Sin embargo, la hostilidad hacia sí mismo del escritor de literatura no la podemos enmarcar como un acto simple de agresión personal, pues puede ocurrir que esa hostilidad o lo que consideramos hostilidad y agresión, no sea más que un proceso de fatiga y agotamiento del ser, de desencantamiento de sí mismo del cual no puede liberarse de otra manera distinta al suicidio. Un ejemplo de ese desencantamiento y fatiga lo podemos ilustrar en el poema Hambre de Jean A. Rimbaud (1988):3

2. Tesis que el autor de este artículo viene trabajando en el estudio del suicidio en intelectuales y corresponde a una interpretación de psicoanalistas dedicados al mismo tema. Su fundamentación será expuesta en forma más amplia en otro artículo en revisión.

3. Se transcribe el poema en forma exacta como aparece en las páginas 155 y ss. de Los Poetas malditos (1998) Editorial Libresa, colección Antares, Quito, Ecuador.. 


\section{HAMBRE}

Sólo mantengo el gusto

por la tierra y por las piedras.

Almuerzo siempre aire,

roca, carbones, hierro.

Girad, hambres mías. Pastad hambres,

en el prado de los sonidos.

Atraed el alegre veneno

de las enredaderas.

Comed los guijarros que se quiebran,

Las viejas piedras de iglesia,

Los cantos rodados de los viejos diluvios,

panes sembrados en los valles grises.

$[\ldots]$

Tuve que viajar, distraer los encantamientos convocados en mi cerebro. Sobre el mar, al que amaba como si hubiera tenido que lavarme una mancha, veía elevarse la cruz consoladora. Había sido condenada por el arco iris. La Dicha era mi fatalidad, mi remordimiento, mi gusano: mi vida sería siempre demasiado inmensa para ser consagrada a la fuerza y a la belleza. ¡La Dicha! Su diente, con extrema dulzura, me advertía con el canto del gallo -ad matutinum, al Christus venit-, en las ciudades sombrías.

¡Oh temporadas, oh castillos!

¿Qué alma existe sin defectos?

He realizado el mágico estudio

de la dicha, que nadie elude.

Salud a ella, cada vez

que cante el gallo galo.

¡Ah! No tendré ya más deseos:

se ha encargado de mi vida.

Este hechizo tomó alma y cuerpo

y dispersó los esfuerzos.

¡Oh temporadas, oh castillos!

La hora de su fuga, iay!

Será la hora de la muerte.

¡Oh temporadas, oh castillos!

Todo esto ha pasado. Hoy sé saludar a la belleza.

La reflexión del pasado y de la vida del escritor puede llevarlo a pensar que ha acumulado una gran carga que no desea llevar, no la soporta, que las satisfacciones producidas ya no le interesan ni las desea en el momento actual, quiere vaciarse y sin 
sentimientos de reproche ni de desesperanza el suicidio es una buena opción para volver al vacío, a la nada. Albert Camus pensaba un poco así, de ahí su famosa frase, tantas veces citada: "No hay más que un problema filosófico verdaderamente serio: el suicidio" (Camus, 1967).

El escritor de literatura puede actuar su suicidio bajo una circunstancia especial que llama la atención a sus lectores: el vacío insostenible e insoportable de la ausencia de creatividad o el deterioro de la misma. Como autor o como narrador puede ser consciente de que la agilidad de la mano se ha empobrecido porque ya no hay en su cerebro generatividad que le ordene la construcción de personajes y tramas para conformar un texto que merezca algún reconocimiento de calidad, por el contrario, se evidencia su decadencia. Un ejemplo es el suicidio del escritor húngaro Arthur Koestler, quien vio disminuida su creatividad ante el padecimiento de una leucemia y el avance de la enfermedad de Parkinson que lo debilitaba física y mentalmente (Koestler, 2011). Confrontar su estancamiento y su vacío, le produce una enorme angustia que absorbe en forma obsesiva y compulsiva su existencia hasta llevarlo al suicidio. Un existencialista imperioso y lapidario dirá: "Ya está en la nada, pues que pase definitivamente a la nada".

Otra perspectiva interesante sobre el suicidio del escritor de literatura, es el descubrimiento de su submundo oscuro e inconsciente, al cual llega ya sea por la existencia traumática de sus personajes o ante la reflexión de la creación de los roles que desempeñan dichos personajes. En ambas circunstancias él hallará esa instancia instintiva, pasional, o de excesiva racionalidad y normatividad, que no había dilucidado en su mundo psíquico y la cuestionará, pues lo abruma. Esto lo induce a su derrumbamiento, sea para crear otro o para desintegrarlo completamente, demoliéndose a sí mismo a través del suicidio. Podríamos debatir si se aniquila por la angustia que esto le produce, o si el acto suicida es causado por el conocimiento de ese submundo hasta ahora desconocido, llevado a la conciencia, que no le satisface y no desea seguir actuando ni le interesa reconstruir de otra manera, y por lo tanto apagar la existencia es la mejor opción.

El afecto del escritor de literatura interviene en la consumación de su suicidio, pues es un ser humano y como tal la afectividad es parte de su sensibilidad artística. Varios escritores suicidas han manifestado, antes de morir y aún después (mediante cartas y documentos) el vacío afectivo que los embargaba y les ocasionaba el sufrimiento. Sylvia Plath, por ejemplo, en febrero de 1956 envió una carta a su médico en la que le manifiesta que volvía a sentir síntomas de depresión y hostilidad, como cuando se intentó suicidar en una ocasión anterior:

Querido doctor: Me encuentro muy mal. He tenido el corazón en un puño con palpitaciones y amagos. De repente, los simples rituales del día se resisten como un caballo terco. Resulta imposible mirar a la gente a la cara. ¿Puede irrumpir de nuevo el mal? ¡Quién sabe! La conversación intrascendente es fatal. 
También la hostilidad aumenta. Esa virulencia peligrosa y devastadora que surge del alma enferma. La mente enferma, también. En nuestro interior se derrumba la imagen de identidad que a diario luchamos por grabar en el mundo indiferente u hostil; y nos sentimos aplastados (Plath, 2013).

Otros se habían alejado de las relaciones afectivas significativas y continuamente estaban en conflicto por ello de forma ambivalente. Algunos escritores suicidas adoptaron una posición consciente de rechazo a toda manifestación afectiva, considerando que lo que ello producía era un sentimiento de apego unilateral o bilateral que no soportaban. Por tanto, al no tener ninguna relación afectiva su suicidio no sería señalado como un acto hostil o agresivo, pues antes había desaparecido afectivamente en los otros.

Existe información de escritores menores suicidas, con ello destaco a aquellos escritores con obras valiosas que por diversas circunstancias no obtuvieron en su momento el reconocimiento que esperaban o sus obras fueron de poca divulgación, con lo cual se creó en ellos una posición ambivalente. Por un lado, el suicidio como escape de la frustración personal y la desesperanza, en cierto modo de protesta a la sociedad pues eran incomprendidos e ignorados. Leopoldo Lugones, por dar un ejemplo, en medio de sus contradicciones políticas, sociales y literarias (Devoto, 2008). Por otro lado, el suicidio como medio de presionar el reconocimiento de su obra, así sea de forma póstuma, que era el objetivo de su existencia, el sacrificio de una vida mortal por la inmortalidad literaria.

Se podría considerar que al suicidarse el escritor de literatura no anhela actuar la muerte sobre el sí mismo real, sino sobre el sí mismo imaginario, el construido a través de un personaje o de varios personajes de sus obras, con los cuales entra en conflicto, pues se siente invadido, amordazado, cuestionado y señalado, características que le limitan su libertad. Solamente matándolo, o matándolos, a través de su suicidio real se puede liberar de ellos.

Algún impertinente agudo dirá: ¿qué pasa cuando el escritor hace que su personaje se suicide y él, como narrador o autor, sigue vivo y no se suicida? Contestarle nos lleva a un campo interesante en donde la reflexión va encaminada no ya al acto suicida sino homicida: se propina la muerte al otro para liberarse de la penetración en la vida del escritor, porque él como persona y ser real no desea morir, lo que desea es hacer desaparecer a ese otro ser que lo invade y se le torna insoportable para la convivencia. En este caso existe una actitud de hostilidad y la agresión puede ser medida por la forma y circunstancias horrorosas que utiliza el escritor para matar a su personaje, y de esa forma, a la vez, acometer un suicidio parcial, concepto que se me ocurre en este momento para designar la liberación definitiva de un ser molesto que habita en nosotros y que necesitamos desdeñar para poder vivir con mayor tranquilidad, pues 
esos personajes como alter ego dan valía a su existencia y por tanto, siente cual dios, que puede hacer con ellos lo que desee.

Otro lector más impertinente y con mayor agudeza podrá preguntar: ¿`si se mata al personaje, pero la ideología de él, su conciencia, sus sentimientos y sus comportamientos yacen en la psique de escritor real, y éste no soporta tal invasión, qué pasa? Podríamos responderle que definitivamente el suicidio real podría ser una opción de libertad. $\mathrm{O}$ también, si tiene fuerzas y motivación, pero no desea suicidarse, podría construir o dar vida a un personaje antagónico que se encargue de liberarlo de aquel que ha asediado y modelado su existencia. Enfrentado el escritor literario al suicidio de sus personajes, puede llegar al pensamiento y a la actuación que como ya no tiene nada más que destruir, el último personaje de su creación es él mismo, por el dolor o la ira que le invade, mata en forma definitiva a su Yo y a su Alter Ego.

Hay escritores de literatura que se suicidaron por padecimientos mentales claramente conocidos: trastorno afectivo bipolar, trastorno depresivo crónico y recurrente, psicosis diversas o algún trastorno de personalidad. En este grupo están: Ernest Hemingway, quien padeció de un trastorno afectivo bipolar; Virginia Woolf, sufrió un trastorno depresivo recurrente; Horacio Quiroga, estados depresivos además de su cáncer de próstata; Alejandra Pizarnik, al igual que Sylvia Plath, padecía estados depresivos recurrentes; Raúl Gómez Jattin, con una enfermedad psicótica, aunque aún se discute si se suicidó o fue un accidente de tránsito. Nos dejó un hermoso poema, $E l$ Suicida (Gómez, 2010):4
Airoso en su galope
levantó la mano armada
hasta su sien
y disparó:
suave derrumbe
del caballo al suelo
Doblado sobre un muslo
cayó
y sin un solo gemido
se fue a galopar
a las praderas del cielo 
María Mercedes Carranza se suicidó bajo episodios de angustia y depresión. Algunos allegados comentan que a la hora de su muerte tenía el poema Epístola Mortal, de su padre Eduardo Carranza (Echavarría, 1996): 5

\section{EPÍSTOLA MORTAL \\ / In memoriam / Leopoldo Panero \\ ...y no hallé cosa en qué poner los ojos \\ que no fuese recuerdo de la muerte. \\ QUEVEDO}

Miro un retrato: todos están muertos:

poetas que adoró mi adolescencia.

Ojeo un álbum familiar y pasan

trajes y sombras y perfumes muertos.

(Desangrados de azul yacen mis sueños).

[...]

"Las torres que desprecio al aire fueron"...

Voy andando entre ruinas y epitafios

por una larga vía de Cipreses

que sombrean suspiros y sepulcros.

Aquí yace mi alma de veinte años

con su rosa de fuego entre los dedos.

Aquí están los escombros de un ensueño.

Aquí yace una tarde conocida.

Y una rosa cortada en una mano

y una mano cortada en una rosa.

Y una cruz de violetas me señala

la tumba de una noche delirante...

[...]

"Sólo que el tiempo lo ha borrado todo

como una blanca tempestad de arena".

El que primero atravesó el océano

volando solo, solo con su arcángel,

y aquel en cuya frente ardía ya

el incendio maldito de Hiroshima,

los guerreros que al aire alzan el brazo

y la palabra libre como un águila

y aviones y estandartes y legiones

pasan cantando, pasan, ya van muertos: 
adelante la muerte va a caballo, en un caballo muerto.

La tierra es un redondo cementerio y el cielo es una losa funeral.

[...]

Somos arrendatarios de la muerte.

(A nuestra espalda, sigilosamente cuando estamos dormidos, sin avisarnos se urden muchas cosas como incendios, naufragios y batallas y terremotos de iracundo puño... que de repente borran de este mundo el rostro del ahora y del ayer, llámase amor o sangre y ojos negros... Y nadie nos había dicho nada.

Alguien sabe el revés de los tapices, digo, de vuestra vida, y es el otro, el fantasma quien lo teje...).

[...]

Tanto amor, tanto anhelo, tanto fuego: dime, oh Dios mío, ¿en cuál mar van a dar? “LLos yunques y troqueles de mi alma trabajan para el polvo y para el viento?". Por el mar, por el aire, por el Llano, por el día, en la noche, a toda hora, vienen vivos y muertos, todos muertos y desembocan en el corazón donde un instante salen a las flores, los labios delirantes y las nubes y siguen tiempo abajo, sangre abajo: isomos antepasados de otros muertos! Todo cae, se esfuma, se despide y yo mismo me estoy diciendo adiós y me vuelvo a mirar, me dejo solo, abandonado en este cementerio. Allá mi corazón está enterrado como una hazaña luminosa y pura. Miro en torno, los ojos entornados: todos estamos contra el paredón: sólo esperamos el tiro de gracia: todos estamos muertos, muertos, muertos: los de ayer, los de hoy, los de mañana... 
sembrados ya de trigo o de palmeras,

de rosales o simplemente yerba:

nadie nos llora, nadie nos recuerda.

Sobre este poema vuela un cuervo.

Y lo escribe una mano de ceniza.

Por último, varios escritores de literatura se suicidaron por no poder soportar la degradación física y los intensos dolores por padecimientos crónicos como el cáncer. Entre ellos Jaime Torres Bodet y Alfonsina Storni, la cual refleja su dolor en su hermoso poema, Dolor (Storni, 2013): ${ }^{6}$

Pasear por la orilla lejana del mar;

Que la arena de oro, y las aguas verdes,

Y los cielos puros me vieran pasar.

Ser alta, soberbia, perfecta, quisiera,

Como una romana, para concordar

Con las grandes olas, y las rocas muertas

Y las anchas playas que ciñen el mar.

Con el paso lento, y los ojos fríos

Y la boca muda, dejarme llevar;

Ver cómo se rompen las olas azules

Contra los granitos y no parpadear

Ver cómo las aves rapaces se comen

Los peces pequeños y no despertar;

Pensar que pudieran las frágiles barcas

Hundirse en las aguas y no suspirar;

Ver que se adelanta, la garganta al aire,

El hombre más bello; no desear amar...

Perder la mirada, distraídamente,

Perderla, y que nunca la vuelva a encontrar;

Y, figura erguida, entre cielo y playa,

Sentirme el olvido perenne del mar. 


\section{El suicidio desde la visión del escritor hacia afuera}

Otras reflexiones sobre el escritor de literatura suicida están dadas en la inmersión de la persona en la cultura que le correspondió vivir. Nadie osa negar las influencias culturales en cada uno de los individuos, y de esa relación con el medio ambiente se modela una visión de mundo adaptativa a él o, por el contrario, en conflicto, en permanente rechazo y queja. Los escritores de literatura son los menos ajenos a la introyección de ese mundo ajeno a él y a la vez inmerso en él. Pues, casi por oficio e interés, lo que narran y construyen está basado en las dinámicas sociales que intervienen en la psique de sus personajes, las circunstancias en las cuales cada uno desarrolla una trama.

El mundo externo deviene al escritor de literatura en su formación personal, en la concepción de la obra y en la creatividad de los rasgos de carácter de sus personajes, todo está allí, no hay forma de escapar. Muchas escuelas de recepción literaria han abordado estas circunstancias, para mencionar algunas de impacto en el tema que se propone:

a. El psicoanálisis se ha dedicado a explicar las obras desde la mirada de la estructura psíquica del escritor, de sus actuaciones y motivaciones, de lo que quieren expresar y la puesta en escena de su inconsciente.

b. Otras han analizado la obra y al escritor desde la estructura del texto y la forma del mismo, para realizar inferencias en las motivaciones y el lenguaje latente, como ocurre con el formalismo ruso y el estructuralismo francés; sirvieron en una época para la censura literaria y la represión del escritor.

c. Algunas teorías de la recepción se han orientado al lector-receptor activo y participante, el cual modula el impacto de la obra y la aceptación o rechazo del escritor.

d. No podía dejar de mencionar la manipulación de la industria editorial y de los medios de comunicación tanto del personaje-escritor como de la obra en sí misma; es bien conocida la exaltación de escritores cuyos textos no resisten un análisis literario serio. Es frecuente ver "escritores de pasarela" como modelos de ropa que se dedican a exaltar más su personalidad neurótica que a la calidad de su producción; no obstante son promovidos como maestros, para luego ser degradados y olvidados.

e. La industria editorial y los medios de comunicación, en general, invisibilizan una obra a través del silencio, aun siendo de gran calidad literaria pues no entra en el marketing editorial. El escritor es concebido como parroquial o escribe en contravía del canon dictado por la industria en su momento.

7. Término que empleo para designar aquellos escritores actuales del marketing editorial, más preocupados por su apariencia personal que por la calidad de sus trabajos escritos. 
Sea la circunstancia social en la cual viva el escritor, es difícil negar que está atento al cariño y aprobación de sus lectores. La dependencia del lector o en nuestra época postmoderna de los medios de comunicación que manejan la industria editorial se hace cada vez más indispensable para ser valorado y divulgado.

De esta relación del escritor con sus lectores o con los medios editoriales y de comunicación, pueden surgir dos posiciones contradictorias. La primera: el deseo de aceptación, en ocasiones excesivo, pero con sentimientos de inseguridad, de rechazo y de intolerancia a las respuestas de su público lector. Segunda: la subvaloración de sí mismo o de su obra, actúa en consecuencia de forma ambivalente con posiciones megalomaníacas extremas o de inhibición social, pues el escritor siempre desarrolla una incapacidad de establecer proyectos verdaderamente creativos porque su atención se desgasta en luchar psíquicamente con su entorno. Las consecuencias son sentimientos de engaño, abandono, desprecio, rechazo y humillación. Además la búsqueda permanente de "algo que no sabe qué es", acompañado de una elevada carga de hostilidad y agresión hacia sí mismo y el mundo que le rodea, genera un exceso de miedo y de angustia.

A la pregunta ¿cómo escapa el escritor de literatura a la angustia que le proporciona el mundo?, su respuesta invita a recordar las enseñanzas de Karen Horney (1981) en su libro La Personalidad neurótica de nuestro tiempo, que dice que podemos escapar de nuestros conflictos de cuatro maneras: racionalizándolos, negándolos, narcotizándolos o evitándolos, y desde la perspectiva de este escrito añadiría una quinta alternativa: el suicidio.

En Les causes du suicide, Halbwasch (1930) fundamenta la "teoría de la subcultura" para explicar el suicidio. Una de sus afirmaciones: "en el origen del acto suicida juegan una gran importancia los significados y motivos situacionales de los individuos", nos da luz sobre qué pretende el escritor de literatura al suicidarse, orientándonos a centrar la búsqueda del significado de su suicidio en el contexto social en que habitó, significados múltiples y contradictorios que pudieron ejercer una fuerza determinante del acto suicida. Es común oír en medios literarios expresiones como: "este mundo es una porquería", "la vida en esta sociedad podrida no vale vivirla", "para qué literatura en esta sociedad de bestias", implicando con ello fastidio, rechazo y hostilidad hacia sí mismo que conduce hacia su destrucción.

El significado del suicidio del escritor de literatura en la sociedad puede enmarcarse en el pensamiento del psicoanalista H. Hendin (1951), en su libro Psychodinamic motivational factors in suicide (1951) manifiesta que el suicidio no es más que un deseo actuado en varias formas que se pueden inferir e interpretar de la siguiente manera: primera, "un deseo cansado de escapar", ¿de qué desea escapar?, preguntamos. Indudablemente escapamos de las contradicciones entre el sí mismo y el entorno, del juego de amor y odio con el mundo de afuera. Segunda, "un deseo culpable de castigo", ¿por qué lo desea?, ¿qué culpa lo embarga? Posiblemente los sentimientos que le deja 
la incomprensión y los actos destructivos que él cree ha realizado. Tercera, "un deseo hostil de venganza", ¿vengarse de qué? Del mundo que lo rechaza, lo desvaloriza y lo desconoce, castigándolo y culpabilizándolo. Cuarto, "un deseo de rendición masoquista apasionada", la muerte es la salida considerada de rendición ante su agresor, significado que da a la sociedad. Quinto, "un deseo esperanzado de rescate", que podría ser ya no el sí mismo, la persona que actúa como escritor de literatura, sino el rescate de su obra escrita y de sus personajes, ya que al morir él, no mueren los personajes que creó ni el contexto de la obra escrita.

El mundo literario no es ajeno a los fenómenos de la envidia y los celos, los cuales ejercen un papel social preponderante para castigar y rechazar al otro que considera amenaza. Asumir la envidia y los celos del mundo hacia afuera, es aceptar las insuficiencias de su carácter para determinar en forma real la valía de la obra literaria escrita y la posición de la persona en el contexto social en que vive. Es una acción de sometimiento al otro, sin crítica y asumiendo la veracidad de los ataques. La consecuencia de este tipo de posiciones es angustia y desestabilización, y de ahí la opción del suicidio por la afrenta al Alter Ego.

De los tres postulados de K. Menninger, expuestos en su libro El hombre contra símismo (1972), podemos considerar el tercero: "el deseo de morir". En un aparte de este breve ensayo, sobre el conflicto del escritor de literatura y el mundo hacia afuera, se resalta que "el deseo de morir se enlaza con los motivos más sofisticados y frecuentemente se interpreta en las ansias de reposo y en la voluntad de alejar o rehuir los conflictos". Algunos escritores han expresado, en forma manifiesta o latente, la necesidad de huir de los conflictos que luego realiza a través del suicidio. Dicha hipótesis puede ilustrar el suicidio del escritor Andrés Caicedo, quien continuamente expresaba que vivir más de 25 años era una insensatez y en varias ocasiones intentó quitarse la vida, hasta que lo consumó el 4 de marzo de 1977, ingiriendo una gran cantidad de barbitúricos. El escritor chileno Albert Fuguet (2008) dice de la muerte de Caicedo:

Es el eslabón perdido del boom. Y el enemigo número uno de Macondo. No sé hasta qué punto se suicidó o acaso fue asesinado por García Márquez y la cultura imperante en esos tiempos. Era mucho menos el rockero que los colombianos quieren, y más un intelectual. Un nerd súper atormentado. Tenía desequilibrios, angustia de vivir. No estaba cómodo en la vida. Tenía problemas con mantenerse de pie. Y tenía que escribir para sobrevivir. Se mató porque vio demasiado.

No podía concluir esta breve exposición del conflicto del escritor de literatura y el mundo hacia fuera sin mencionar la reflexión de E. M. Ciorán en su libro La tentación de existir (2002) al referirse al intelectual que considera el suicidio: 
El intelectual fatigado resume las deformidades y los vicios de un mundo a la deriva. No actúa: padece; si se vuelve hacia la idea de tolerancia, no encuentra en ella el excitante que necesita. Es el terror quien se lo proporciona, lo mismo que las doctrinas de las que es desenlace. ¿Qué él es la primera víctima? No se quejará. Sólo le sucede la fuerza que le tritura. Querer ser libre es querer ser uno mismo; pero él ya está harto de ser él mismo, de caminar en lo incierto, de errar a través de las verdades. -Ponedme las cadenas de la ilusión-, suspira, mientras dice adiós a las peregrinaciones del Conocimiento. Así se lanzará de cabeza en cualquier mitología que le asegure la protección y la paz del yugo. Declinando el honor de asumir sus propias ansiedades, se comprometerá en empresas de las que obtendrá sensaciones que no sabría conseguir de sí mismo, de suerte que los excesos de su cansancio reforzarán las tiranías.

\section{Preguntas a manera de conclusión y de reflexión}

¿Qué espera un escritor al abandonar el mundo de los vivos e introducirse en el mundo desconocido de los muertos?

$¿$ Es la muerte del escritor de literatura o de sus personajes un principio de realidad?

$¿$ ¿l escritor de literatura se suicida por el principio de realidad o por la fantasía de poseerla?

¿Al poner la imaginación al servicio de la realidad la agota, la suprime y la consecuencia es el hastío y el suicidio?

$¿ E$ ¿ escritor de literatura vive en constante búsqueda de objetos perdidos y al no hallarlos, no lo soporta y se suicida?

¿Fracasó el escritor de literatura en su deseo de hacerse significativo en el universo de los otros, o del sí mismo fantaseado, y por ello se suicida?

¿El escritor de literatura agotó sus preguntas y su espíritu pensante, y a causa de esto se suicida?

\section{Referencias}

ALARCÓN-VELANDIA, R.P. (2013). Por qué se suicidan los escritores de literatura. Pereira: libro en preparación.

CAMUS, A. (1967). El Mito de Sísifo. Madrid: Ediciones Aguilar.

CARRANZA, E. (1996). La Epistola Mortal en Rogelio Echevarría, Antología de la poesía colombiana, Tomo II. Bogotá: Editorial Imprenta Nacional

CIORÁN, E.M. (2002). La tentación de existir. Madrid: Santillana Ediciones. 
DEVOTO, F. (2008). "Acerca de un intelectual extremo y sus fracasos. El caso de Leopoldo Lugones político”. Estudios sociales, Rev. Universitaria semestral. XVIII (34). Santafé, Argentina: Universidad Nacional del Litoral.

ECHAVARRÍA, R. (1996). Antología de la poesía colombiana. Tomo II. Bogotá: Editorial Imprenta Nacional.

FUGUET, A. (2008). Andrés Caicedo. Mi cuerpo es una celda: una autobiografia. Bogotá: Editorial Norma.

GÓMEZ JATTIN, R. (2010). Amanecer en el Valle del Sinú. Bogotá: Fondo de Cultura Económica.

HALBWASCH, M. (1930). Les causes du suicide. París: Edit. Felix Alcan.

HENDIN, H. (1951). Psychodinamic motivational factors in suicide. Psychiatry Quartely. 25: 672-678.

HORNEY, K. (1981). La personalidad neurótica de nuestro tiempo. Buenos Aires: Editorial Paidos.

KOESTLER, A. (2011). Memorias. Madrid: Editorial Lumen.

MENNINGER, K. (1972). El hombre contra símismo. Barcelona: Editorial Península.

PLATH, S. (2013) Ellaberintoliterario.blogtspot.com/2013/poesía-sylviaplath.html 16/o2/2013

RIMBAUD, J. A. (1988). Los poetas malditos. Quito: Libresa.

SILVA, J. A. (1984). Poesía y Prosa. Colección Joyas de la literatura colombiana. Bogotá: Círculo de Lectores

STORNI, A. (2013). Dolor. www.lospoetas.com, Julio 25/2013. 